\title{
Administration of Iodine-125 Seeds Promotes Apoptosis in Cholangiocarcinoma through the PI3K/Akt Pathway
}

\author{
Junqing Lin $(\mathbb{D}$, Leye Yan, Xiaolong Wang, Zhengzhong Wu, Kun Ke, Xin Lin, Ning Huang, \\ and Weizhu Yang 1
}

Department of Interventional Radiology, Fujian Medical University Union Hospital, Fuzhou 350001, China

Correspondence should be addressed to Weizhu Yang; drweizhuyang@163.com

Received 30 December 2021; Accepted 26 January 2022; Published 24 February 2022

Academic Editor: Changlei Xia

Copyright (C) 2022 Junqing Lin et al. This is an open access article distributed under the Creative Commons Attribution License, which permits unrestricted use, distribution, and reproduction in any medium, provided the original work is properly cited.

\begin{abstract}
Purpose. We aimed to examine the effects of ${ }^{125} \mathrm{I}$ seeds on the gene expression of Bcl-2, Bax, and PI3K/Akt pathway components in cholangiocarcinoma cells. Methods. In vitro, human cholangiocarcinoma RBE cells were treated with ${ }^{125} \mathrm{I}$ seeds $(0.39 \mathrm{mCi}$ or $0.85 \mathrm{mCi}$ ) for $72 \mathrm{~h}, 120 \mathrm{~h}$, and $168 \mathrm{~h}$. Cell proliferation and apoptosis were assessed. The expression of Bcl-2 and Bax was detected by RT-PCR, and Western blotting was carried out to explore changes in Akt activity. Result. ${ }^{125} \mathrm{I}$ seeds inhibited the proliferation of RBE cells. The apoptosis rate of the RBE cells in the low-activity group was significantly higher than that in the high-activity group at $120 \mathrm{~h}$ and $168 \mathrm{~h}$, while no difference was found between the two groups at $72 \mathrm{~h}$. After $120 \mathrm{~h}$ of culture, the gene expression of Bcl-2 and Bax decreased in both groups, the ratio of $\mathrm{Bcl}-2 / \mathrm{Bax}$ in the low-activity group decreased, and the PI3K/Akt signaling pathway was inhibited in both groups. Conclusion. ${ }^{125} \mathrm{I}$ seeds affect the proliferation and apoptosis of cholangiocarcinoma cells in a dose-dependent manner. The therapeutic effect of low-activity ${ }^{125} \mathrm{I}$ seeds on cancer cells may be better. ${ }^{125}$ I seed brachytherapy may promote the apoptosis of cholangiocarcinoma cells by inhibiting the PI3K/Akt signaling pathway and regulating the $\mathrm{Bcl}-2 / \mathrm{Bax}$ ratio.
\end{abstract}

\section{Introduction}

Cholangiocarcinoma (CCA) is the second most common malignant liver carcinoma, accounting for $3 \%$ of gastrointestinal cancer cases and $15 \%$ of all primary hepatic tumor cases $[1,2]$. The incidence and mortality of CCA have been steadily increasing in recent decades, especially in Asian countries $[3,4]$. CCA is a highly aggressive tumor that is associated with a high mortality rate due to late diagnosis and infective treatment [5]. Early-stage CCA can be treated by surgical resection alone or in combination with liver transplantation. However, at the time of diagnosis, the majority of patients (>65\%-80\%) are in an advanced stage of disease, with unresectable or distant metastasis, and no effective chemotherapies or molecular targeted therapies are available for these patients [6]. Therefore, there is an urgent need to develop new therapeutic strategies for CCA.
${ }^{125}$ I seed brachytherapy is an established approach for the treatment of a variety of tumors, such as hepatocellular carcinoma, prostate cancer, lung cancer, and pulmonary cancer, and has resulted in excellent outcomes. ${ }^{125}$ I seed brachytherapy has been demonstrated to be an effective modality with advantages of maximal antitumor effects, minimal toxicity and morbidity, slow and continuous irradiation release, convenience, short hospital stay, and longterm efficacy $[7,8]$. To date, ${ }^{125}$ I seed implantation alone or in combination with biliary stents has been used in CCA patients to evaluate the benefits.

Apoptosis, DNA damage, G2/M phase cell cycle arrest, autophagy, and paraptosis are possible mechanisms underlying the effect of ${ }^{125} \mathrm{I}$ seed radiation on various types of cancer [9-11]. Apoptotic programmed cell death plays a key role in a number of human physiological and pathological processes via the extrinsic (death receptor) and intrinsic (mitochon- 


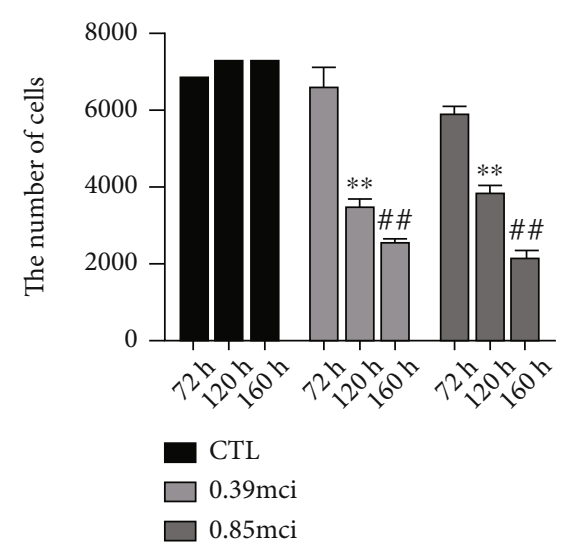

FIgUre 1: Proliferation analysis of the RBE cells treated with lowactivity $(0.39 \mathrm{mCi})$, high-activity $(0.85 \mathrm{mCi})$, and control groups at $72 \mathrm{~h}, 120 \mathrm{~h}$, and $168 \mathrm{~h}$. Significant difference was detected between the low-activity and control groups $\left({ }^{* *} P<0.001\right)$, as well as the high-activity and control groups ( $\left.{ }^{\#} P<0.00\right)$.

drial) pathways [12-14]. Mitochondrial apoptosis is tightly controlled by BCL-2 family proteins, including apoptosisinhibiting molecules (such as Bcl-2) and apoptosispromoting molecules (such as Bax) [15].

The phosphatidylinositol 3 '-kinase (PI3K)/Akt pathway is a key regulator of cellular functions, including proliferation, migration, invasion, and survival, and appears to be crucial in cancer [16]. Akt regulates a variety of biological processes, including the inhibition of apoptosis, which is mediated by the direct phosphorylation of apoptotic signaling molecules or the indirect modulation of transcription factor activity [17]. Moreover, through inactivating the original prosurvival Bcl-2 family members, Akt negatively regulates the expression or function of $\mathrm{Bcl}-2$ homology domain 3-only proteins [18]. Therefore, in the present study, we investigated whether ${ }^{125}$ I seeds can be exploited as a novel effective strategy for treating CCA via the regulation of BCL-2 family proteins by PI3K signaling.

\section{Methods and Materials}

2.1. Cell Culture. Human cholangiocarcinoma RBE cells were provided by the Cell Bank of Type Culture Collection of the Chinese Academy of Sciences (Shanghai, China). RBE cells were cultured in RPMI 1640 culture medium (Gibco, Carlsbad, CA) supplemented with $10 \%$ fetal bovine serum and $1 \%$ penicillin-streptomycin in a humidified incubator containing $5 \% \mathrm{CO}_{2}$ at $37^{\circ} \mathrm{C}$. The media were replaced every other day. When the cells formed a $70 \%-80 \%$ confluent monolayer, they were detached with $0.25 \%$ trypsinEDTA and dissociated into a single-cell suspension for further cell culture and assays.

2.2. Radiation Source. The ${ }^{125} \mathrm{I}$ seeds used during the study period were kindly provided by Jaco Pharmaceuticals Company Limited (Ningbo, China). The ${ }^{125}$ I seeds had a half-life of 59.4 days, were $4.5 \mathrm{~mm}$ in length and $0.8 \mathrm{~mm}$ in diameter, and were sterilized by high-temperature sterilization. Cells were cultured at a density of 2000 cells/well in 96-well plates.
After overnight culture, one sterilized ${ }^{125}$ I seed was placed in the center of each of 6 wells, and these wells were divided into the low-activity $(0.39 \mathrm{mCi} / \mathrm{seed})$, high-activity $(0.85 \mathrm{mCi} / \mathrm{seed})$, and control treatment groups.

2.3. Cell Apoptosis Assay. After ${ }^{125}$ I seed treatment, Hoechst/ PI double staining was performed, and cell apoptosis was assessed through high-content screening. Cells were cultured at a density of 2000 cells/well in 96-well plates and treated with low-activity ${ }^{125} \mathrm{I}$ seeds, high-activity ${ }^{125} \mathrm{I}$ seeds, or no ${ }^{125}$ I seeds in the center of each of 6 wells. Each sample was analyzed at $72 \mathrm{~h}, 120 \mathrm{~h}$, and $168 \mathrm{~h}$. The apoptosis rate was expressed as the percentage of the highest target total intensity.

2.4. Real-Time PCR Analysis. RBE cells were collected $120 \mathrm{~h}$ after irradiation, and ribonucleic acid (RNA) was isolated from the cultured cells. Total RNA was extracted by Biozol (BioFlux, Japan), and reverse transcription was performed with a PrimeScript RT Kit (Takara Bio Inc., Japan) according to the manufacturer's protocol. The synthesized cDNA was quantified with a LightCycler 96 Real-Time PCR system (Roche, UK) and SYBR Premix Ex Taq (Tli RNaseH Plus) (Takara Bio Inc., Japan). The specificity of the primers was verified by analyzing the melting curve. The expression level was standardized by the internal reference gene GAPDH, and the relative expression was determined by the $2^{-\Delta \Delta \mathrm{Ct}}$ method. Quantitative real-time PCR was used to assess the relative $\mathrm{Bcl}-2$ and $\mathrm{Bax}$ gene expression levels.

2.5. Western Blotting Analysis. Cell lysates were obtained after treatment with high- or low-activity seeds for $120 \mathrm{~h}$, subjected to SDS-polyacrylamide gel electrophoresis, and immunoblotted with primary antibodies (rabbit monoclonal anti-phospho-Akt; Ser473: Cell Signaling Technology, USA), followed by horseradish peroxidase-conjugated secondary antibodies. The bands were visualized by enhanced chemiluminescence (ECL, Thermo Scientific Pierce, USA) using a lumino image analyzer. The images were processed and analyzed by the ImageJ software.

2.6. Statistical Analysis. All the data are expressed as the mean \pm standard deviation $(x \pm s)$. A $t$ test was used to compare the mean values of two groups. The statistical significance of mean differences between studied groups was evaluated by two-way ANOVA and Dunnett's test. Statistical significance was defined as a $P$ value $<0.05$. Statistical calculations were performed with the SPSS 13.0 software.

\section{Results}

3.1. Proliferation Analysis. RBE cells were treated with ${ }^{125} \mathrm{I}$ seeds of different activities, and the proliferation of the RBE cells was detected by a high-content screening instrument at $72 \mathrm{~h}, 120 \mathrm{~h}$, and $168 \mathrm{~h}$. There was no significant difference in cell proliferation between the high-activity group and the low-activity group after 72 hours of incubation, but significant differences were detected at 120 hours and 168 hours. With the increase in treatment time, the number of proliferating cells decreased significantly, and there was a 

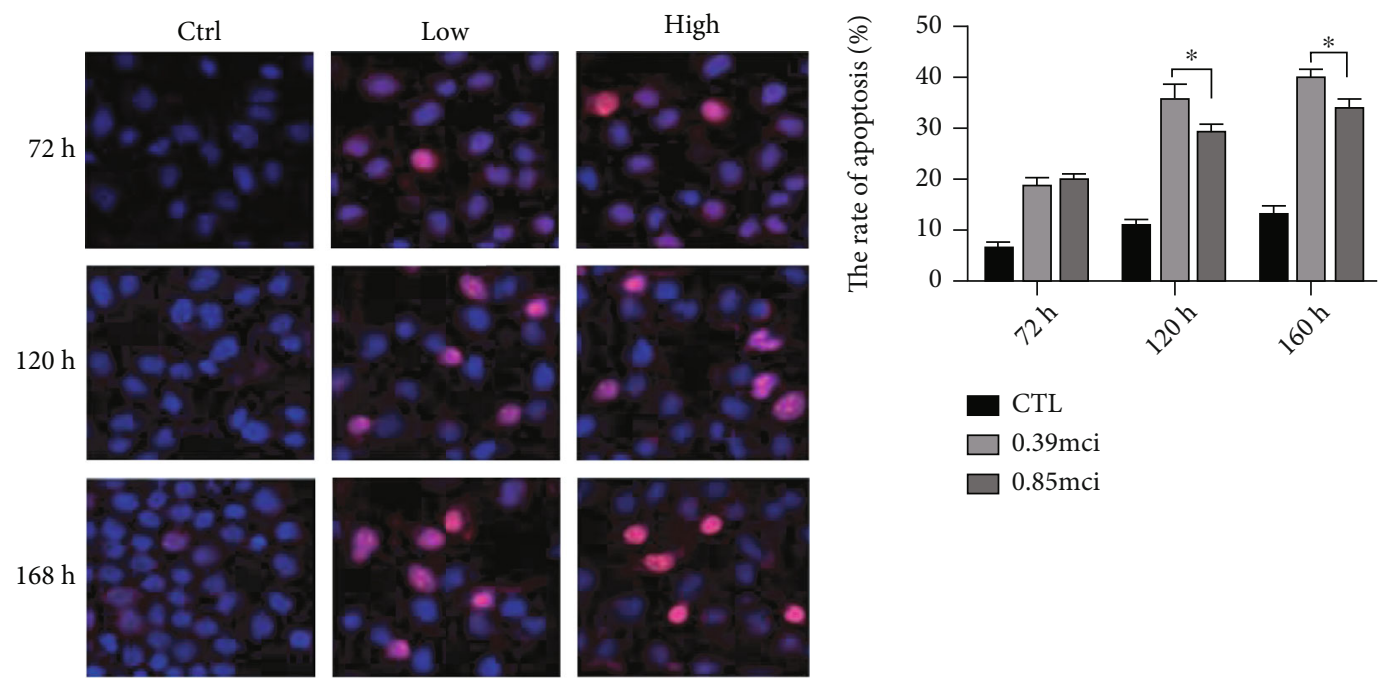

(a)

(b)

FIgURE 2: Apoptosis analysis of the RBE cells treated with low-activity $(0.39 \mathrm{mCi})$, high-activity $(0.85 \mathrm{mCi})$, and control groups at $72 \mathrm{~h}$, $120 \mathrm{~h}$, and $168 \mathrm{~h}$. (a) Hoechst/PI double staining and (b) cell apoptosis rate was performed through high-content screening $\left({ }^{*} P<0.05\right)$.

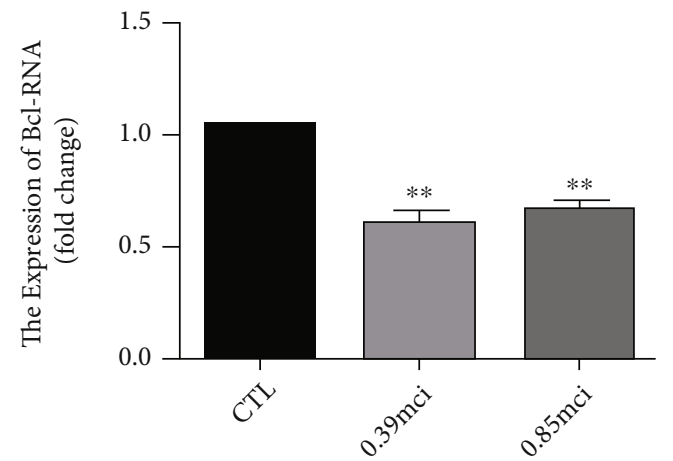

(a)

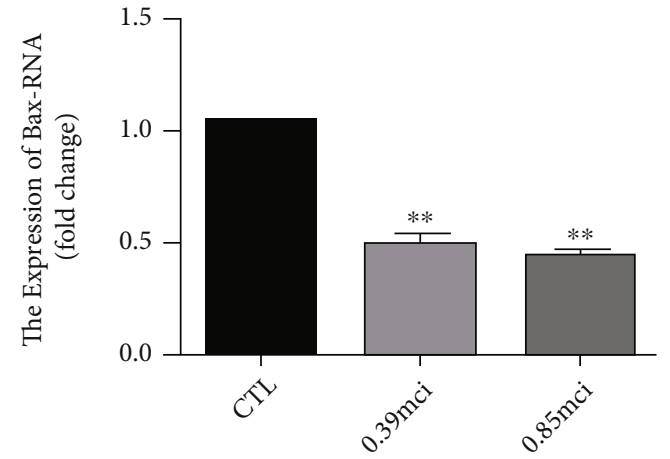

(b)

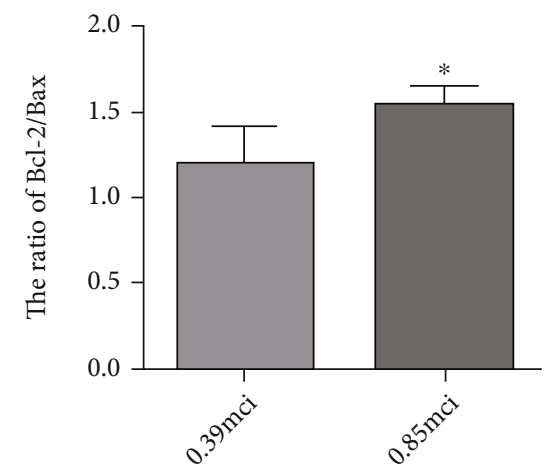

(c)

FIGURE 3: Bcl-2 and Bax gene expression levels in the control group, low-activity group, and high-activity group by RT-PCR. (a) RNA levels of Bcl-2. (b) RNA levels of Bax. (c) The ratio of $\mathrm{Bcl}-2 / \mathrm{Bax}\left({ }^{*} P<0.05,{ }^{* *} P<0.001\right)$.

significant difference within each group except for the control group, while there was no significant difference between the high-activity group and the low-activity group. The rate of cell proliferation inhibition increased with time (Figure 1).
3.2. Apoptosis Analysis. The apoptosis rates of the RBE cells treated with low-activity and high-activity ${ }^{125} \mathrm{I}$ seeds were significantly higher than that of the RBE cells treated with control after $72 \mathrm{~h}, 120 \mathrm{~h}$, and $168 \mathrm{~h}$ of treatment. At $72 \mathrm{~h}$, the apoptosis rate of RBE cells in the low-activity group 


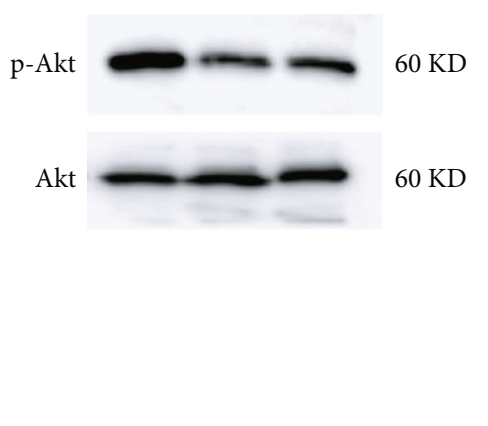

(a)

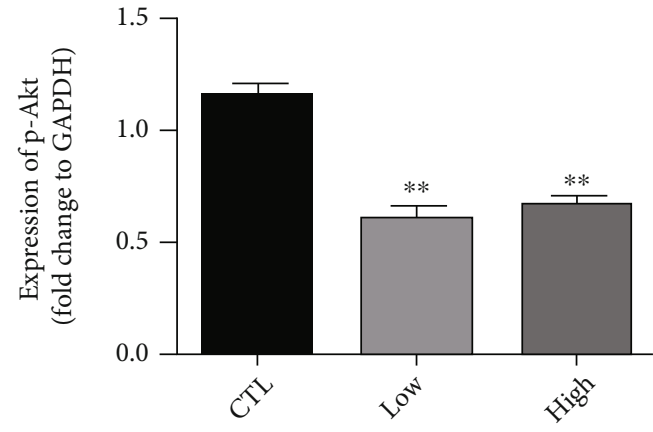

(b)

FIgURE 4: Expression of p-Akt in the cells treated with high- and low-activity ${ }^{125}$ I seeds for $120 \mathrm{~h}$. (a) Western blotting analysis of expression of p-Akt. (b) Histograms relative to the quantification of the marker bands in (a) $\left({ }^{* *} P<0.001\right)$.

$(0.39 \mathrm{mCi})$ was not significantly different from that in the high-activity group $(0.85 \mathrm{mCi})$, but at $120 \mathrm{~h}$ and $168 \mathrm{~h}$, the difference was statistically significant $(P<0.05)$ (Figure 2$)$.

3.3. Bcl-2 and Bax Gene Expression Levels. After the cells were treated with high- and low-activity ${ }^{125}$ I seeds for 120 hours, the levels of Bcl-2 and Bax RNA expression were detected in the control group, low-activity group, and high-activity group. The expression of $\mathrm{Bcl}-2$ and $\mathrm{Bax}$ was decreased in both the low- and high-activity groups. The expression of $\mathrm{Bcl}-2$ in the low-activity group was lower than that in the high-activity group, while the expression of Bax in the low-activity group was higher than that in the highactivity group. The ratio of $\mathrm{Bcl}-2 / \mathrm{Bax}$ was 1.20 in the low-activity group and 1.56 in the high-activity group (Figure 3).

3.4. PI3K/Akt Signaling Pathway. Western blotting was used to detect the expression of p-Akt in the cells treated with high- and low-activity ${ }^{125} \mathrm{I}$ seeds for $120 \mathrm{~h}$. The level of $\mathrm{p}$ Akt in the low- and high-activity groups was significantly lower than that in the control group. However, there was no significant difference in the level of phosphorylated Akt between the low-activity and high-activity groups (Figure 4).

\section{Discussion}

CCA is a rare cancer that constitutes a diverse group of malignancies emerging from the biliary tree $[19,20]$. However, CCA has been a global health problem, and its global incidence and mortality have increased in recent decades. CCA is often asymptomatic at an early stage and diagnosed at an advanced stage, resulting in a poor prognosis. Thus, novel therapeutic strategies need to be developed. ${ }^{125} \mathrm{I}$ seed implantation alone or in combination with biliary stents has been used in CCA patients, indicating that ${ }^{125} \mathrm{I}$ seed treatment is an effective adjuvant therapy [21-23].

Previous studies have reported that irradiation-induced apoptosis became more obvious when the radiation dose increased [24], which is similar to the results of the present study. In our study, we found that cell proliferation was not significantly affected in either the low-activity group or the high-activity group after 72 hours of treatment. At 120 hours and 168 hours, the proliferation of cells in the lowactivity group and high-activity group was significantly inhibited, and it increased with time. It is suggested that the inhibitory effects of ${ }^{125} \mathrm{I}$ seeds on tumor cells are dosedependent. Moreover, there was no significant difference in the apoptosis rate at 72 hours. However, at 120 hours and 168 hours, the apoptosis rate of the low-activity group was higher than that of the high-activity group, which was consistent with other studies [25]. Therefore, a lower dose was also more effective in inducing apoptosis in cancer cells. It is worth noting that the effect of promoting tumor cell apoptosis in the low-activity group was better than that in the high-activity group, which may be related to the reactive protection of cells after injury.

The Bcl-2 family plays a pivotal role in apoptosis progression and can activate cell death by activating the mitochondrial pathway. The Bcl-2 family can be divided into three groups: prosurvival BCL-2-like proteins, multi-BH domain proapoptotic $\mathrm{BAX} / \mathrm{BAK}$ proteins, and proapoptotic $\mathrm{BH} 3$-only proteins [26]. Bcl-2 family genes are also involved in the imbalance of cell growth and death in some cancers, which may be related to $\mathrm{BH} 3$ domain mutations in proapoptotic and antiapoptotic proteins. Overexpression of members of the BCL-2 protein family that block apoptosis contributes to malignant transformation [27]. There is potential evidence that inhibition of $\mathrm{Bcl}-2$-like protein expression can be a therapeutic strategy for cancer. Several studies revealed that ${ }^{125}$ I seed radiation could significantly upregulate the expression of Bax protein and downregulate the expression of Bcl-2 protein in lung cancer cells $[25,28]$. Consistent with the above reports, current results supported that ${ }^{125} \mathrm{I}$ seed brachytherapy upregulates Bax RNA expression and downregulates $\mathrm{Bcl}-2$ RNA expression, especially in the lowactivity group. Furthermore, the ratio of $\mathrm{Bcl}-2 / \mathrm{Bax}$ in the low-activity group was lower than that in the high-activity group, which indicated that the treatment effect in the lowactivity group is better than that in the high-activity group.

Moreover, the PI3K/Akt signaling pathway plays a vital role in cellular processes, including cell proliferation, differentiation, and migration, apoptosis, and autophagy, as well as in maintaining many basic physiological functions, such as nutrient absorption, ribosome synthesis, and intracellular metabolism. Akt mainly includes three isoforms, AKT1, 
AKT2, and AKT3, that share a common structure and a similar activation mechanism [29]. All three subtypes have highly conserved domains at the $\mathrm{N}$-terminus. After activation by phosphorylation of Thr308 or Ser473, Akt is transferred into the cytoplasm or nucleus, phosphorylates a variety of downstream protein substrates, and regulates various cell processes, including metabolism, proliferation, survival, transcription, and angiogenesis. Akt also affects $\mathrm{Bcl}-2$ family proteins, which play a regulatory role in metabolism, survival, and proliferation. Akt activates the antiapoptotic role of $\mathrm{Bcl}-2$ and $\mathrm{Bcl}-\mathrm{xL}$ by facilitating the interaction between phosphorylated BAD and 14-3-3 protein and inhibiting the activity of caspase-9. Furthermore, activated AKT translocates to various intracellular locations and phosphorylates and modulates the function of numerous substrates that are involved in cancer initiation and progression [29]. Several studies have suggested that the AKT signaling pathway plays an essential role in ${ }^{125} \mathrm{I}$ seeds-based radiotherapy of cancer cells $[9,10,30-32]$. In our study, the level of phosphorylation of PI3K/Akt pathway components was detected to assess the activation of the PI3K/Akt pathway. The phosphorylation of Akt in the lowactivity group and high-activity group was lower than that in the control group, but there was no significant difference in the level of pathway activation between these two groups. Radiation from ${ }^{125}$ I seeds downregulated the expression of p-Akt, and ${ }^{125} \mathrm{I}$ seed radiation-induced apoptosis in CCA may be caused by the inhibition of activation of Akt signaling.

There are some limitations in this study. First, the ${ }^{125} \mathrm{I}$ seed irradiation scheme designed in this experiment has the disadvantage of uneven irradiation. Then, the cumulative dose received using only one ${ }^{125} \mathrm{I}$ seed could not be calculated from the corresponding activity of the treatment in this study. Further in vivo studies need to be performed to verify the results of this in vitro experiment.

\section{Conclusion}

${ }^{125}$ I seeds affect the proliferation and apoptosis of cholangiocarcinoma cell lines. The therapeutic effect of low-activity ${ }^{125}$ I seeds on cancer cells may be better than that of highdose ${ }^{125}$ I seeds. ${ }^{125}$ I seed therapy may affect the balance of $\mathrm{Bcl}-2 / \mathrm{Bax}$ by regulating the activity of the PI3K/Akt signaling pathway.

\section{Data Availability}

The data used to support the findings of this study are included within the article.

\section{Conflicts of Interest}

The authors report no conflict of interest.

\section{Acknowledgments}

This work is sponsored by grants from the Fujian Provincial Department of Science and Technology (2019J01162).

\section{References}

[1] J. M. Banales, J. J. G. Marin, A. Lamarca et al., "Cholangiocarcinoma 2020: the next horizon in mechanisms and management," Nature Reviews. Gastroenterology \& Hepatology, vol. 17, no. 9, pp. 557-588, 2020.

[2] I. Ntanasis-Stathopoulos, D. I. Tsilimigras, M. Gavriatopoulou, D. Schizas, and T. M. Pawlik, "Cholangiocarcinoma: investigations into pathway-targeted therapies," Expert Review of Anticancer Therapy, vol. 20, no. 9, pp. 765773, 2020.

[3] C. J. O'Rourke, J. Lafuente-Barquero, and J. B. Andersen, "Epigenome remodeling in cholangiocarcinoma," Trends in Cancer, vol. 5, no. 6, pp. 335-350, 2019.

[4] P. M. Rodrigues, P. Olaizola, N. A. Paiva et al., "Pathogenesis of cholangiocarcinoma," Annual Review of Pathology, vol. 16, no. 1, pp. 433-463, 2021.

[5] P. Bertuccio, M. Malvezzi, G. Carioli et al., "Global trends in mortality from intrahepatic and extrahepatic cholangiocarcinoma," Journal of Hepatology, vol. 71, no. 1, pp. 104-114, 2019.

[6] D. Dondossola, M. Ghidini, F. Grossi, G. Rossi, and D. Foschi, "Practical review for diagnosis and clinical management of perihilar cholangiocarcinoma," World Journal of Gastroenterology, vol. 26, no. 25, pp. 3542-3561, 2020.

[7] F. Li, L. Wang, Y. Zhang et al., "A retrospective study on using a novel single needle cone puncture approach for the iodine125 seed brachytherapy in treating patients with thoracic malignancy," Frontiers in Oncology, vol. 11, article 640131, 2021.

[8] J. Lin, H. Jiang, W. Yang et al., "Predictive factors of benefit from iodine-125 brachytherapy for hepatocellular carcinoma with portal vein tumor thrombosis," Brachytherapy, vol. 18, no. 2, pp. 233-239, 2019.

[9] L. Hu, H. Wang, Y. Zhao, and J. Wang, "125I seeds radiation induces paraptosis-like cell death via PI3K/AKT signaling pathway in HCT116 cells," BioMed Research International, vol. 2016, Article ID 8145495, 2016.

[10] C. Wang, T. K. Li, C. H. Zeng et al., "Iodine125 seed radiation induces ROS mediated apoptosis, autophagy and paraptosis in human esophageal squamous cell carcinoma cells," Oncology Reports, vol. 43, no. 6, pp. 2028-2044, 2020.

[11] J. Lin, W. Yang, N. Jiang et al., "Incidence and prediction of seed migration to the chest after iodine-125 brachytherapy for hepatocellular carcinoma," Brachytherapy, vol. 16, no. 6, pp. 1252-1256, 2017.

[12] R. A. Lockshin, "Programmed cell death 50 (and beyond)," Cell Death and Differentiation, vol. 23, no. 1, pp. 10-17, 2016.

[13] H. Flores-Romero, O. Landeta, B. Ugarte-Uribe et al., "BFL1 modulates apoptosis at the membrane level through a bifunctional and multimodal mechanism showing key differences with BCLXL," Cell Death and Differentiation, vol. 26, no. 10, pp. 1880-1894, 2019.

[14] C. Boedicker, M. Hussong, C. Grimm et al., "Co-inhibition of BET proteins and $\mathrm{PI} 3 \mathrm{~K} \alpha$ triggers mitochondrial apoptosis in rhabdomyosarcoma cells," Oncogene, vol. 39, no. 19, pp. 3837-3852, 2020.

[15] T. P. Garner, D. Amgalan, D. E. Reyna, S. Li, R. N. Kitsis, and E. Gavathiotis, "Small-molecule allosteric inhibitors of BAX," Nature Chemical Biology, vol. 15, no. 4, pp. 322330, 2019. 
[16] C. Porta, C. Paglino, and A. Mosca, "Targeting PI3K/Akt/ mTOR signaling in cancer," Frontiers in Oncology, vol. 4, p. 64, 2014.

[17] A. Bender, D. Opel, I. Naumann et al., "PI3K inhibitors prime neuroblastoma cells for chemotherapy by shifting the balance towards pro-apoptotic Bcl-2 proteins and enhanced mitochondrial apoptosis," Oncogene, vol. 30, no. 4, pp. 494-503, 2011.

[18] Y. He, M. M. Sun, G. G. Zhang et al., "Targeting PI3K/Akt signal transduction for cancer therapy," Signal Transduction and Targeted Therapy, vol. 6, no. 1, p. 425, 2021.

[19] J. M. Banales, V. Cardinale, G. Carpino et al., "Cholangiocarcinoma: current knowledge and future perspectives consensus statement from the European Network for the Study of Cholangiocarcinoma (ENS-CCA)," Nature Reviews. Gastroenterology \& Hepatology, vol. 13, no. 5, pp. 261-280, 2016.

[20] S. Rizvi, S. A. Khan, C. L. Hallemeier, R. K. Kelley, and G. J. Gores, "Cholangiocarcinoma - evolving concepts and therapeutic strategies," Nature Reviews. Clinical Oncology, vol. 15, no. 2, pp. 95-111, 2018.

[21] X. Hu, Q. Pang, H. Liu et al., "Inflammation-based prognostic scores in patients with extrahepatic bile duct lesions treated by percutaneous transhepatic biliary stenting combined with (125)I seeds intracavitary irradiation," Clinical \& Translational Oncology, vol. 21, no. 5, pp. 665-673, 2019.

[22] Q. Pang, L. Zhou, X. S. Hu et al., "Biliary stenting alone versus biliary stenting combined with $125 \mathrm{I}$ particles intracavitary irradiation for the treatment of advanced cholangiocarcinoma," Scientific Reports, vol. 9, no. 1, article 11348, 2019.

[23] H. W. Wang, X. J. Li, S. J. Li, J. R. Lu, and D. F. He, "Biliary stent combined with iodine-125 seed strand implantation in malignant obstructive jaundice," World Journal of Clinical Cases, vol. 9, no. 4, pp. 801-811, 2021.

[24] J. X. Ma, Z. D. Jin, P. R. Si et al., "Continuous and low-energy 125I seed irradiation changes DNA methyltransferases expression patterns and inhibits pancreatic cancer tumor growth," Journal of Experimental \& Clinical Cancer Research, vol. 30, no. 1, p. 35, 2011.

[25] Z. Wang, Z. Zhao, J. Lu et al., "A comparison of the biological effects of $125 \mathrm{I}$ seeds continuous low-dose-rate radiation and 60Co high-dose-rate gamma radiation on non-small cell lung cancer cells," PLoS One, vol. 10, no. 8, article e0133728, 2015.

[26] A. R. Delbridge and A. Strasser, "The BCL-2 protein family, BH3-mimetics and cancer therapy," Cell Death and Differentiation, vol. 22, no. 7, pp. 1071-1080, 2015.

[27] L. M. Brown, D. T. Hanna, S. L. Khaw, and P. G. Ekert, "Dysregulation of BCL-2 family proteins by leukemia fusion genes," The Journal of Biological Chemistry, vol. 292, no. 35, pp. 14325-14333, 2017.

[28] A. Qu, H. Wang, J. Li et al., "Biological effects of (125)i seeds radiation on A549 lung cancer cells: G2/M arrest and enhanced cell death," Cancer Investigation, vol. 32, no. 6, pp. 209-217, 2014.

[29] M. Shariati and F. Meric-Bernstam, "Targeting AKT for cancer therapy," Expert Opinion on Investigational Drugs, vol. 28, no. 11, pp. 977-988, 2019.

[30] J. Liu, H. Wang, A. Qu, J. Li, Y. Zhao, and J. Wang, "Combined effects of C225 and 125-iodine seed radiation on colorectal cancer cells," Radiation Oncology, vol. 8, no. 1, p. 219, 2013.
[31] C. Liu, L. Wang, H. Qiu et al., "Combined strategy of radioactive 125I seeds and salinomycin for enhanced glioma chemoradiotherapy: evidences for ROS-mediated apoptosis and signaling crosstalk," Neurochemical Research, vol. 43, no. 7, pp. 1317-1327, 2018.

[32] J. H. Rong, D. Li, and Y. L. Li, "Lobaplatin enhances radioactive 125I seed-induced apoptosis and anti-proliferative effect in non-small cell lung cancer by suppressing the AKT/mTOR pathway," Oncotargets and Therapy, vol. 14, pp. 289-300, 2021. 